\title{
Effect of Huaier on the proliferation and apoptosis of human gastric cancer cells through modulation of the PI3K/AKT signaling pathway
}

\author{
HUA-XIA XIE $^{1 *}$, ZHI-YUAN XU ${ }^{1 *}$, JIA-NING TANG ${ }^{1}$, YI-AN DU $^{2}$, \\ LING HUANG $^{2}$, PENG-FEI YU ${ }^{2}$ and XIANG-DONG CHENG ${ }^{1}$ \\ ${ }^{1}$ Department of Gastrointestinal Surgery, The First Affiliated Hospital of Zhejiang Chinese Medical University, \\ Hangzhou, Zhejiang 310006; ${ }^{2}$ Department of Abdominal Surgery, Zhejiang Cancer Research Institute, \\ Zhejiang Cancer Hospital, Hangzhou, Zhejiang 310022, P.R. China
}

Received July 15, 2014; Accepted June 2, 2015

DOI: $10.3892 /$ etm.2015.2600

\begin{abstract}
The aim of the present study was to investigate the effect of Huaier on the proliferation and apoptosis of the MKN45 and SGC7901 gastric cancer cell lines. The MTT assay was used to measure the effects of Huaier on the growth of the cells, while cell cycle distribution and apoptosis levels were analyzed using flow cytometry. Western blotting was used to assess the levels of proteins associated with the apoptotic pathway. It was found that cell survival decreased with the increase in the concentration of Huaier, and the apoptosis rates were increased in a dose-dependent manner both in MKN45 and SGC7901 cells. The number of cells in the G2/M phase in the Huaier-treated groups was increased in a dose-dependent manner compared with that in the control group. Huaier inhibited phosphorylated- (p-)AKT1, phosphatidylinositol 3-kinase (PI3K), pyruvate dehydrogenase kinase isoform 1, p-phosphatidylinositol 3,4,5-trisphosphate 3-phosphatase and dual-specificity protein phosphatase and B-cell lymphoma 2 expression and upregulated cleaved-caspase- 9 expression in a dose-dependent manner. In conclusion, Huaier can strongly inhibit gastric cancer cell proliferation by inhibiting cyclin B1 expression, promoting G2/M-phase arrest and modulating the PI3K/AKT signaling pathway, and can induce gastric cancer cell apoptosis by modulating the PI3K/AKT signaling pathway in dose-dependent manner.
\end{abstract}

Correspondence to: Dr Xiang-Dong Cheng, Department of Gastrointestinal Surgery, The First Affiliated Hospital of Zhejiang Chinese Medical University, 54 Youdian Road, Hangzhou, Zhejiang 310006, P.R. China

E-mail: getfar@vip.sina.com

*Contributed equally

Key words: Huaier, alanine aminotransferase assay, gastric cancer, MKN45, SGC7901, apoptosis

\section{Introduction}

Gastric cancer is among the most common types of cancer, and is a leading cause of cancer-related mortality in Asia (1). The disease is difficult to cure, even with surgical resection and chemotherapy. Currently, although chemotherapy has become a main treatment for gastric cancer, its therapeutic effect is dissatisfactory. Multidrug resistance is one of the leading factors underlying chemotherapy failure (2). It is therefore necessary to develop a new drug that can reverse chemotherapy drug resistance or enhance the sensitivity to chemotherapy.

Huaier has been used for the treatment of several diseases, such as viral hepatitis, in China for a number of years (3); however, it has only been used as a supplementary anti-cancer therapy since the recent discovery of its anti-tumor effect (4). The effective ingredient of Huaier, which is isolated from the extract of the fermented Huaier fungus, has been confirmed to be a proteoglycan with the following constituents: Water, 8.72\%; amino acids, $12.93 \%$; and polysaccharides, $41.53 \%(5,6)$. Huaier has been shown to be effective against several types of cancer, exerting its anti-cancer activity through the inhibition of tumor growth, the induction of apoptosis and through anti-angiogenic effects $(7,8)$; however, to the best of our knowledge, there have been no studies to date about the effects of Huaier on gastric cancer cells.

The phosphatidylinositol 3-kinase (PI3K)/AKT signaling pathways plays a vital role in the resistance to chemotherapy and radiotherapy, as it is associated with a number of processes involved in cell survival, including cell growth, proliferation, movement, apoptosis and angiogenesis. In this study, the anti-proliferative and apoptosis-promoting effects of Huaier on gastric cancer cells and the associated mechanisms were investigated.

\section{Materials and methods}

Ethics statement. All study methods were approved by the Ethics Committee of the First Affiliated Hospital of Zhejiang Chinese Medical University (Hangzhou, China). 
Materials. Aqueous Huaier extract was purchased from Gaitianli Pharmacy Co., Ltd. (Qidong, China). A total of $1 \mathrm{~g}$ electuary ointment was dissolved in $10 \mathrm{ml}$ complete medium and sterilized with a $0.22-\mathrm{mm}$ filter to obtain the $100 \mathrm{mg} / \mathrm{ml}$ stock solution, which was stored at $-20^{\circ} \mathrm{C}$ in RPMI- 1640 medium (Gibco ${ }^{\circledR}$, Hangzhou MultiSciences Biotech Co., Ltd., Hangzhou, China). Fetal bovine serum (FBS) was provided by Gibco, and MTT and dimethyl sulfoxide (DMSO) were purchased from Sigma-Aldrich (St. Louis, MO, USA). The BD Cycletest ${ }^{\mathrm{TM}}$ Plus DNA Reagent kit, FACSCalibur ${ }^{\mathrm{TM}}$ flow cytometer, annexin V/fluorescein isothiocyanate (FITC) kit and propidium iodide (PI) were supplied by BD Biosciences (San Jose, CA, USA).

Cell culture. The MKN45 and SGC7901 human gastric cancer cell lines were obtained from the Cell Bank of the Chinese Academy of Sciences (Shanghai, China). The two cell lines were cultured in RPMI-1640 medium supplemented with $10 \%$ (v/v) FBS, $100 \mathrm{U} / \mathrm{ml}$ penicillin and $100 \mu \mathrm{g} / \mathrm{ml}$ streptomycin at $37^{\circ} \mathrm{C}$ in a humidified atmosphere with $5 \% \mathrm{CO}_{2}$. The cells were subcultured every 2 days.

MTT assay. The effect of Huaier on MKN45 and SGC7901 gastric cancer cell proliferation was assessed using MTT. Exponentially growing cells were seeded into 96-well plates at $4 \times 10^{3}$ cells/well for viability measurements and incubated for $24 \mathrm{~h}$. Different concentrations of Huaier (1, 2, 4, 8 and $16 \mathrm{mg} / \mathrm{ml}$ ) were added to wells and incubated for various durations at $37^{\circ} \mathrm{C}$. On the day of collection, the cell number was measured 24, 48 and $72 \mathrm{~h}$ after incubation using a standard MTT-based assay. A total of $100 \mu \mathrm{l}$ MTT (working concentration, $1 \mathrm{mg} / \mathrm{ml}$ ) was added to each well, and the cells were subsequently incubated at $37^{\circ} \mathrm{C}$ for $4 \mathrm{~h}$. Following the removal of the supernatant, $200 \mu \mathrm{l}$ DMSO was added to dissolve the formazan crystals, and the optical density was detected at $570 \mathrm{~nm}$ using a microplate spectrophotometer (SpectraMax ${ }^{\circledR}$; Molecular Devices, LLC, Sunnyvale, CA, USA). The data represent the mean of three readings, and each dose was tested in triplicate.

Apoptosis. The level of cell apoptosis was evaluated by assessing annexin $\mathrm{V}$-positive staining using flow cytometry. A total of $1 \times 10^{5}$ cells/well was seeded in six-well plates. The cells were incubated with Huaier $(2.5$ and $5 \mathrm{mg} / \mathrm{ml}$ ) or in Huaier-free medium as a control. After $24 \mathrm{~h}$ of incubation, the cells were collected using gentle agitation and washed twice with phosphate-buffered saline (PBS). The cells were resuspended in $100 \mu \mathrm{l}$ binding buffer at a density of $0.5 \times 10^{6}$ cells $/ 100 \mu 1$. Annexin V/FITC (5 $\mu$ l) was added to the cell suspension, which was incubated for a further $10 \mathrm{~min}$ at room temperature. The cells were washed and resuspended in $200 \mu \mathrm{l}$ binding buffer, and PI staining solution was added prior to flow cytometry being performed. In total, 5,000-10,000 events were analyzed using a FACScan ${ }^{\mathrm{TM}}$ machine (BD Biosciences). The apoptosis rate was determined using CellQuest ${ }^{\mathrm{TM}}$ software (BD Biosciences).

Cell cycle analysis. The cell cycle analysis was performed using the standard method with certain modifications (9). Following digestion using trypsin, the cells were resuspended and washed twice with PBS, and then $1 \times 10^{5}$ cells/well were seeded in six-well plates for overnight incubation. At the end of the incubation period, once the cells had adhered to the side wall, the Huaier extract stock solution was diluted to the final concentrations of $0,2.5$ and $5 \mathrm{mg} / \mathrm{ml}$, respectively. Each concentration was used in three parallel control wells. Following the addition of the stock solution, $1 \mathrm{ml}$ was centrifuged and the supernatant was discarded. The three solutions of the BD Cycletest Plus DNA Reagent kit (BD Biosciences) were then added in sequence: i) $250 \mu \mathrm{l}$ solution $\mathrm{A}$, which contained trypsin in a spermine tetrahydrochloride detergent buffer for the enzyme-mediated disaggregation of the solid tissue fragments and the digestion of cell membranes and cytoskeletons, was first added for $10 \mathrm{~min}$ of incubation at room temperature; ii) $250 \mu \mathrm{l}$ solution $\mathrm{B}$ (BD Biosciences), which contained trypsin inhibitor and ribonuclease $\mathrm{A}$ in citrate-stabilizing buffer with spermine tetrahydrochloride for the inhibition of trypsin activity and the digestion of RNA, was then added for a further $10 \mathrm{~min}$ of incubation at room temperature; and iii) $200 \mu \mathrm{l}$ cold solution $\mathrm{C}$, which contained PI and spermine tetrahydrochloride in citrate stabilizing buffer, was added for the stoichiometric binding of the PI to the DNA (final concentration, $\geq 125 \mu \mathrm{g} / \mathrm{ml}$ ). Following the addition of solutions A, $\mathrm{B}$ and $\mathrm{C}$, a mesh filter was used to filter the resulting solution, which was then analyzed after 48 and $72 \mathrm{~h}$ using flow cytometry. The cell cycle was analyzed using ModFit software obtained from CellQuest (BD Biosciences).

Western blot analysis. The cells were plated in $3.5-\mathrm{cm}$ dishes at a density of $2 \times 10^{5}$ and collected following treatment. The cells were placed in lysis buffer (Biyuntian Biotech Co., Ltd, Shanghai, China) according to the manufacturer's instructions. Using $12 \%$ SDS-PAGE, equal quantities of protein ( $20 \mathrm{mg}$ per lane) were separated and transferred to polyvinylidene membranes (Millipore, Billerica, MA, USA). Following the blocking of the membranes, primary monoclonal antibodies against a number of proteins associated with the PI3K/AKT signaling pathway were added and the membranes were incubated overnight at $4^{\circ} \mathrm{C}$. Primary monoclonal antibodies against AKT (1:1,000; 10176-2-AP), PDK1 (1:1,000; 10026-1-AP), Bcl-2-associated death promoter (BAD; 1:1,000; 10435-1-AP) and GAPDH (1:4,000; 60004-1-Ig) were purchased from Proteintech (Manchester, UK), while monoclonal antibodies against p-AKT (The-308; 1:800; 2118-1), p-AKT (Ser-473; 1:800; 2214-1), PI3K (1:1,000; 1593-S), PTEN (1:1,000; 5171-1), p-PTEN (1:1,000; 2134-1), Bcl-2 (1:1,000; 10026-1-AP), pro-caspase-9 $(1: 1,000 ; 1023-1)$ and cyclin B1 $(1: 2,000 ; 1495-1)$ were obtained from Abcam (Cambridge, UK), and monoclonal anti-cleaved-caspase-9 (1:1,000; sc-22182) was from Santa Cruz Biotechnology, Inc. (Shanghai, China). Subsequently, the membranes were labeled with the appropriate secondary antibodies conjugated with horseradish peroxidase (1:5,000; GB23301), purchased from Wuhan Gugeshengwu Technology Co., Ltd. (Wuhan, China). GAPDH was used as the loading control. An enhanced chemiluminescence system (Pierce, Rockford, IL, USA) was used to visualize the immunoreactive bands.

Statistical analysis. Data are expressed as the mean \pm standard deviation. Statistical treatment was performed using SPSS 16.0 software (SPSS, Inc., Chicago, IL, USA). The 

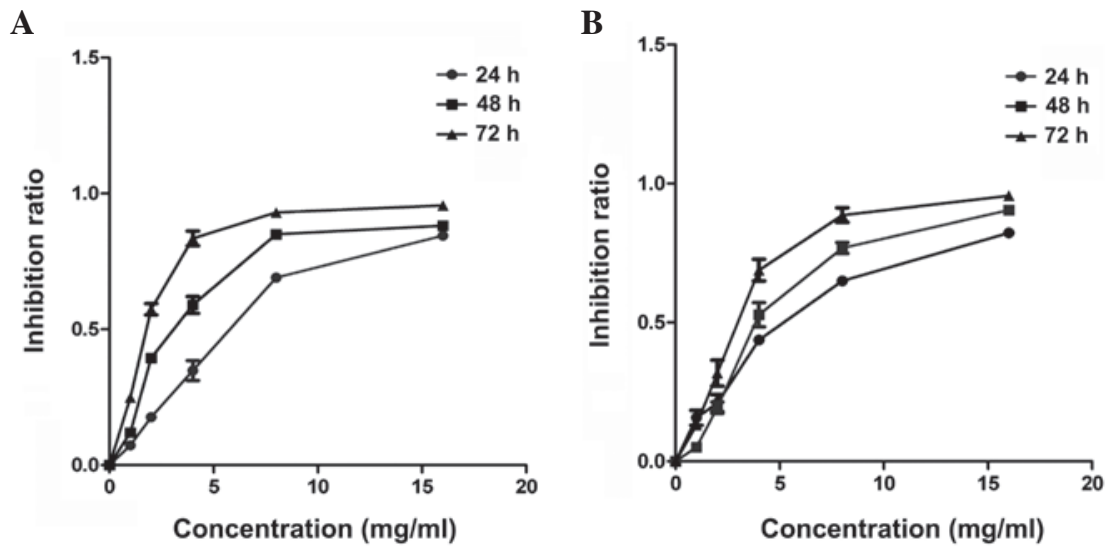

Figure 1. Inhibitory effect of Huaier on gastric cancer cell proliferation in vitro. The growth inhibitory effect of Huaier was measured using the MTT assay. (A) MKN45 and (B) SGC7901 cells were treated with different concentrations of Huaier (0,1,2, 4, 8 and $16 \mathrm{mg} / \mathrm{ml})$ for 24, 48 and $72 \mathrm{~h}$. The experiments were performed in triplicate, and the data are presented as the mean \pm standard deviation of three separate experiments.

A

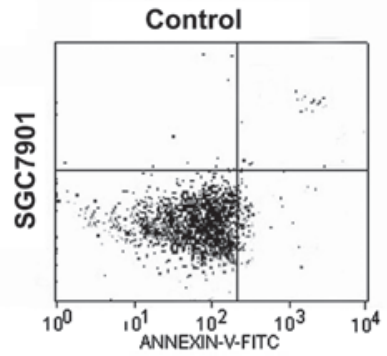

B
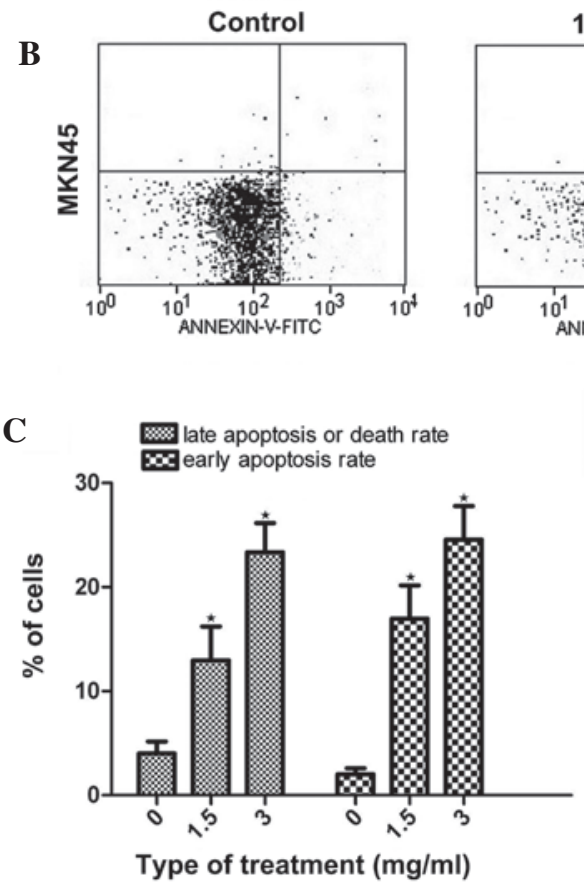

$1.5 \mathrm{mg} / \mathrm{ml}$
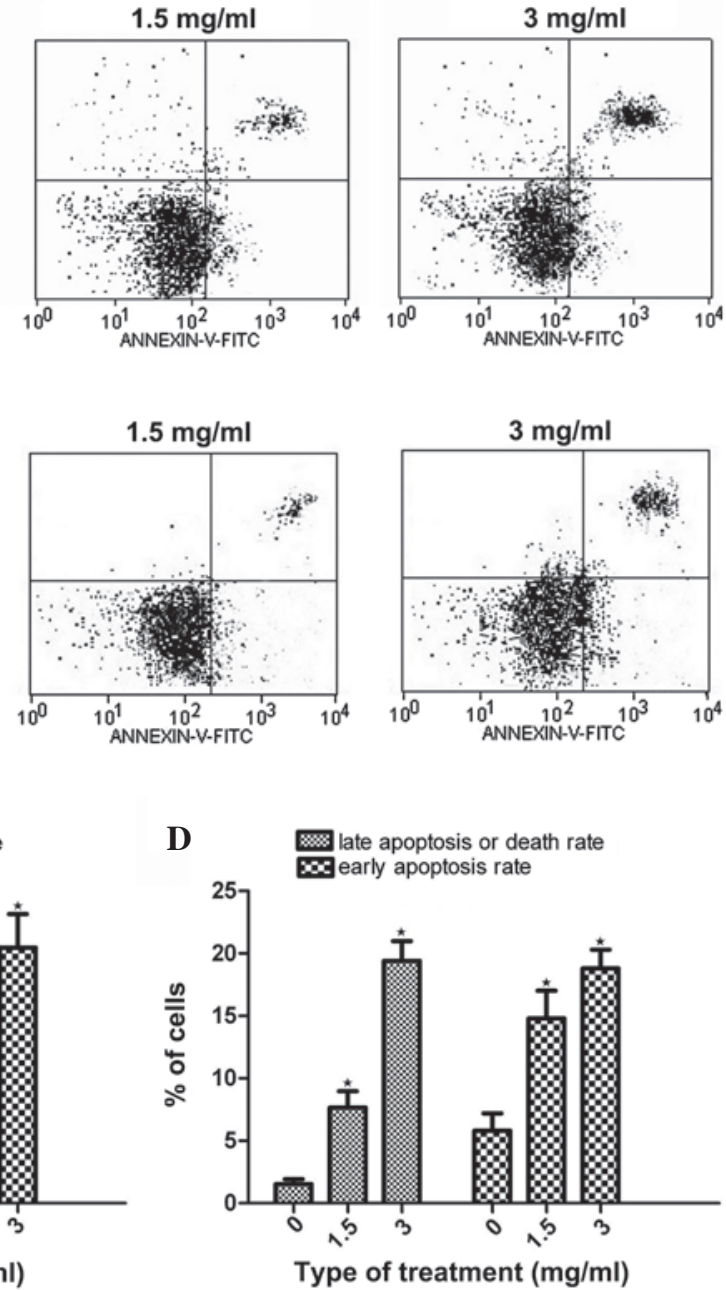

Figure 2. Flow cytometric analysis of PI-annexin-V to quantify Huaier-induced apoptosis in (A and C) SGC7901 and (B and D) MKN45 cells. Dot plots show the results following the treatment of the SGC7901 and MKN45 cells with Huaier at concentrations of $0,1.5 \mathrm{and} 3 \mathrm{mg} / \mathrm{ml}$ for $24 \mathrm{~h}$. The experiment was performed in triplicate, and the data are expressed as the mean \pm standard deviation of the three separate experiments. "P<0.05, compared with the control. PI, propidium iodide; FITC, fluorescein isothiocyanate.

one-tailed Student's t-test was used to analyze differences in drug response between groups, and data were collected from three different experiments. $\mathrm{P}<0.05$ was considered to indicate a statistically significant difference.

\section{Results}

Inhibitory effects of Huaier on gastric cancer cell growth. To evaluate the biological activity of Huaier in cancer cells, 
A

B

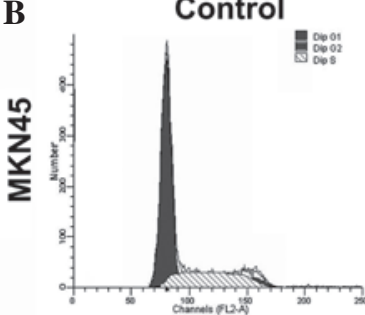

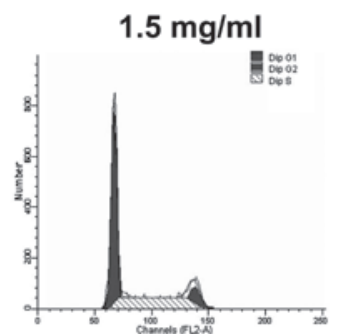

$1.5 \mathrm{mg} / \mathrm{ml}$

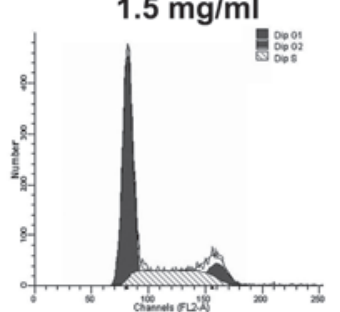

$3 \mathrm{mg} / \mathrm{ml}$
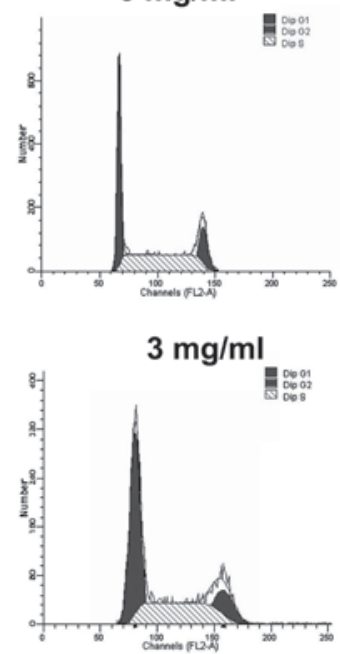
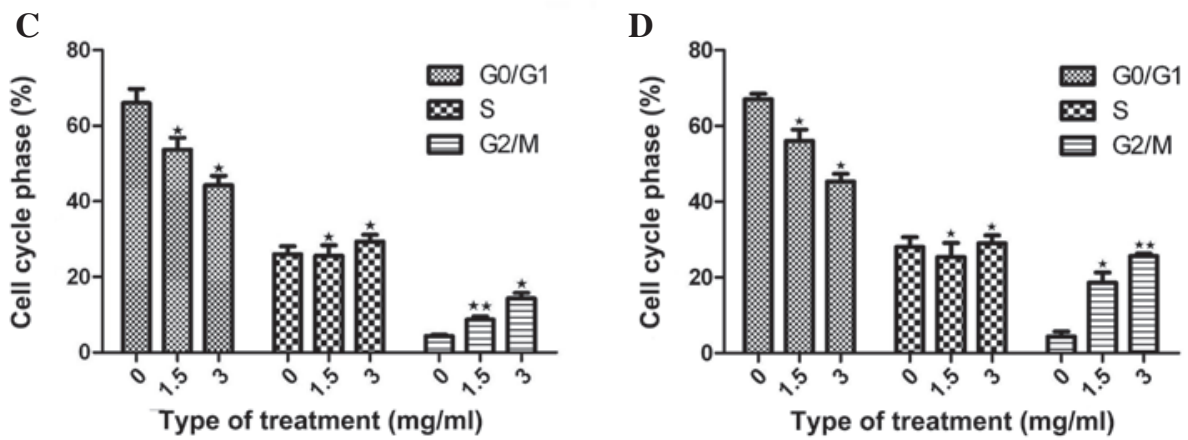

Figure 3. Huaier-induced cell-cycle arrest at G2/M phase in (A and C) SGC7901 and (B and D) MKN45 cells. SGC7901 and MKN45 cells were treated with Huaier at concentrations of $0,1.5$ and $3 \mathrm{mg} / \mathrm{ml}$ for $24 \mathrm{~h}$. The experiment was performed in triplicate, and the data are expressed as the mean \pm standard deviation of the three separate experiments. ${ }^{*} \mathrm{P}<0.05$ and ${ }^{* *} \mathrm{P}<0.01$, compared with the control.

cell viability was measured using the MTT assay following treatment with various concentrations of Huaier. Cell survival decreased with the increase in the concentration of Huaier, and the $\mathrm{IC}_{50}$ was determined to be $2.104 \mathrm{mg} / \mathrm{ml}$ for MKN45 cells and $3.579 \mathrm{mg} / \mathrm{ml}$ for SGC7901 cells (Fig. 1). The results indicated that Huaier had an anti-proliferative effect against gastric cancer cells.

Analysis of cell apoptosis using PI-annexin V staining. As Huaier significantly inhibited cell growth, it was investigated whether this effect was achieved by inducing apoptosis. The PI-annexin V staining assay showed that, following the treatment of the gastric cancer cells with Huaier for $24 \mathrm{~h}$, the late-apoptosis or cell death rate (upper right quadrant) and the early-apoptosis rate (lower right quadrant) were increased in a dose-dependent manner, both in the MKN45 and SGC7901 cells (Fig. 2).

Huaier induces cell-cycle arrest. To investigate whether the inhibition induced by Huaier extract was a result of cell-cycle arrest, the distribution of the MKN45 and SGC7901 gastric cancer cells across the cell cycle was analyzed using flow cytometry. Prior to analysis, the cells were exposed to Huaier for $24 \mathrm{~h}$ at concentrations of 1.5 and $3 \mathrm{mg} / \mathrm{ml}$. Compared with the untreated cells, an increased proportion of Huaier-treated MKN45 and SGC7901 gastric cancer cells was found to be in
G2/M phase, indicating cell-cycle arrest $(\mathrm{P}<0.05)$. Furthermore, the number of cells in $\mathrm{G} 2 / \mathrm{M}$ phase in the Huaier-treated groups was increased in a dose-dependent manner compared with that in the control group (Fig. 3). These results indicated that the inhibitory effect of Huaier on MKN45 and SGC7901 gastric cancer cell proliferation occurred via cell-cycle arrest at G2/M phase (Fig. 3).

Huaier downregulates proteins associated with the apoptosis signaling pathway. The activation of the PI3K/AKT signaling pathway can lead to cell apoptosis; therefore, the expression of proteins associated with the PI3K/AKT signaling pathway, including AKT1, pyruvate dehydrogenase kinase isoform 1 (PKD1), PI3K and phosphatidylinositol 3,4,5-trisphosphate 3-phosphatase and dual-specificity protein phosphatase (PTEN) was assessed using western blotting. To further investigate the mechanisms through which Huaier induces apoptosis and cell-cycle arrest, the expression of cyclin B1, B-cell lymphoma 2 (Bcl-2) and caspase-9 was measured using western blotting. The results indicated that Huaier inhibited cyclin B1, phosphorylated- (p-)AKT1, PI3K, PDK1, p-PTEN and $\mathrm{Bcl}-2$ expression and upregulated cleaved-caspase-9 expression in a dose-dependent manner (Figs. 4 and 5). Caspase-9 activation was significantly increased following treatment with Huaier extract, resulting in increased cleaved caspase- 9 expression and decreased pro-caspase- 9 expression. 

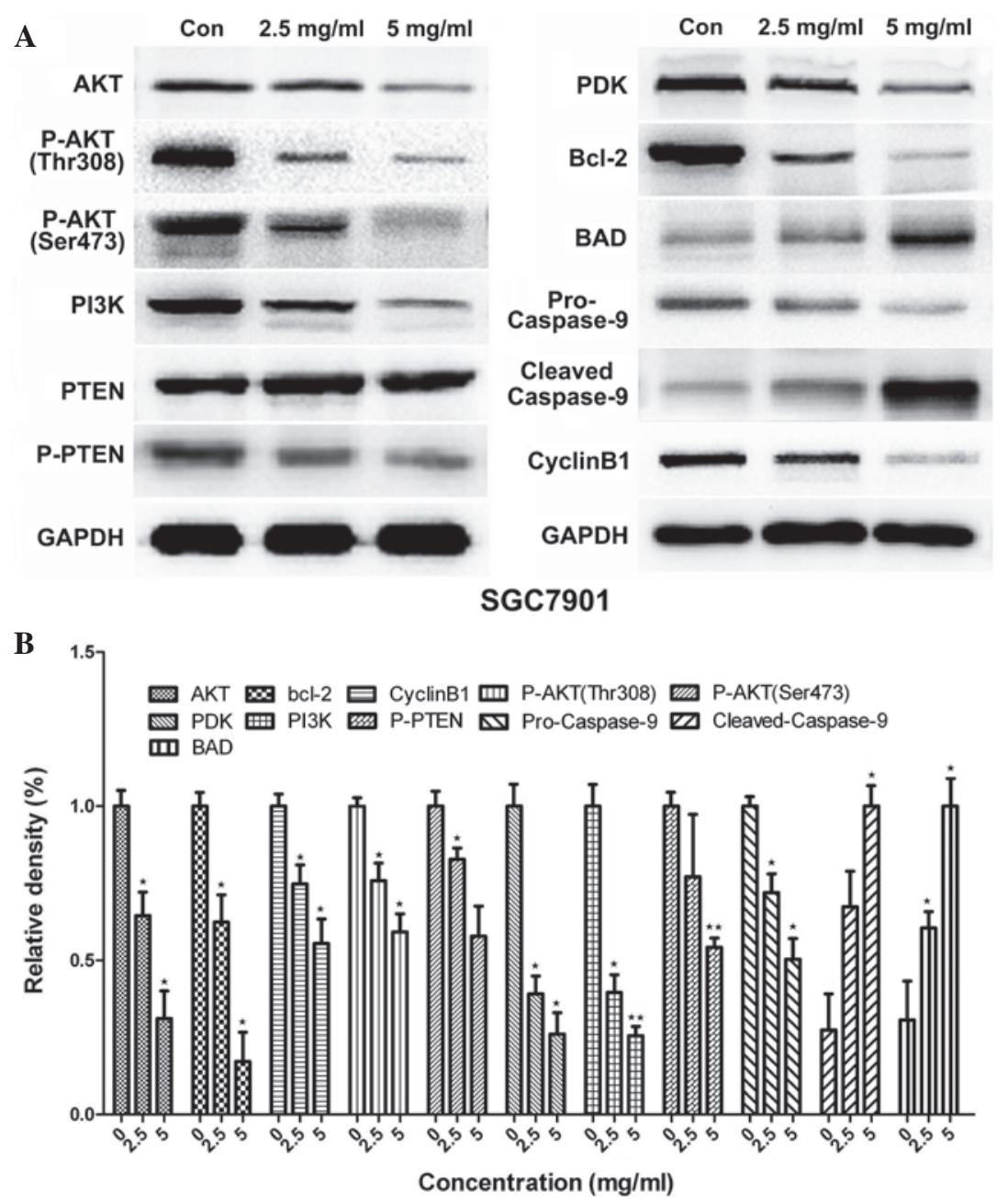

Figure 4. Effect of Huaier extract on the protein expression of AKT1, PI3K, PTEN, PDK1, caspase-9 and Bcl-2 in SGC7901 cells. The expression of GAPDH was used as an internal control. The SGC7901 cells were treated with $0,2.5$ and $5 \mathrm{mg} / \mathrm{ml} \mathrm{Huaier}$ for $24 \mathrm{~h}$, and (A) western blotting was used to analyze the protein expression. (B) Quantification of the data. The experiment was performed in triplicate, and the data are expressed as the mean \pm standard deviation of the three separate experiments. ${ }^{*} \mathrm{P}<0.05$ and ${ }^{* *} \mathrm{P}<0.01$, compared with the control. p-, phosphorylated-; PI3K, phosphatidylinositol 3-kinase; PTEN, phosphatidylinositol 3,4,5-trisphosphate 3-phosphatase and dual-specificity protein phosphatase; PDK1, pyruvate dehydrogenase kinase isoform 1; Bcl-2, B-cell lymphoma 2; BAD, Bcl-2-associated death promoter.

\section{Discussion}

Gastric cancer is one of the most common types of malignant tumor in the world. The early prognosis associated with gastric cancer is poor, as the condition is characterized by early lymphatic metastasis with high malignancy. The current main treatment for gastric cancer is surgery, in conjunction with chemotherapy and other comprehensive treatments; however, the drug resistance of gastric cancer has become a problem in the clinic, and certain patients experience pain with chemotherapy. The development of safe and effective drugs to inhibit cancer cell proliferation is therefore currently an area of particular interest. In recent years, Huaier, which is extracted from officinal fungi, has been shown to inhibit the proliferation of various types of cancer cells: Hepatocellular carcinoma (8), breast cancer (10), cholangiocarcinoma (11), melanoma (12), colorectal cancer (13) and ovarian cancer (14). However, the antitumor mechanism of Huaier has yet to be fully elucidated; therefore, the aim of the present study was to investigate the mechanism underlying the Huaier-induced cell apoptosis. The results indicated that, in addition to inhibiting cell proliferation, Huaier could induce cell apoptosis by modulating the PI3K/AKT signaling pathways.

PI3Ks, the second messengers produced by phosphoinositide phosphorylate at the D-3 position of the inositol ring, are involved in a number of cellular activities and can promote several biological properties, including proliferation, survival, motility and morphology (15). AKT plays vital roles in the signaling pathways in response to growth factors and other extracellular stimuli to regulate various cellular functions, including nutrient metabolism and cell growth, survival and apoptosis (16). AKT, a downstream effector of PI3K, is activated by Class $1 \mathrm{~A}$ and $1 \mathrm{~B}$ PI3Ks, while the Class $1 \mathrm{~A}$ and $1 \mathrm{~B}$ PI3Ks are activated by tyrosine kinase and G-protein-coupled receptors, respectively (17). Following the activation of PI3K, phosphatidylinositol 4,5-biphosphate on the 3-OH group generates the second messenger phosphatidylinositol 3,4,5-trisphosphate (PIP3). PIP3 levels are regulated by phosphatases such as PTEN, which removes the phosphate from the 3-OH position (16). The present results suggested that Huaier inhibited the expression of AKT, p-AKT, PTEN and p-PTEN by downregulating PI3K. 
A
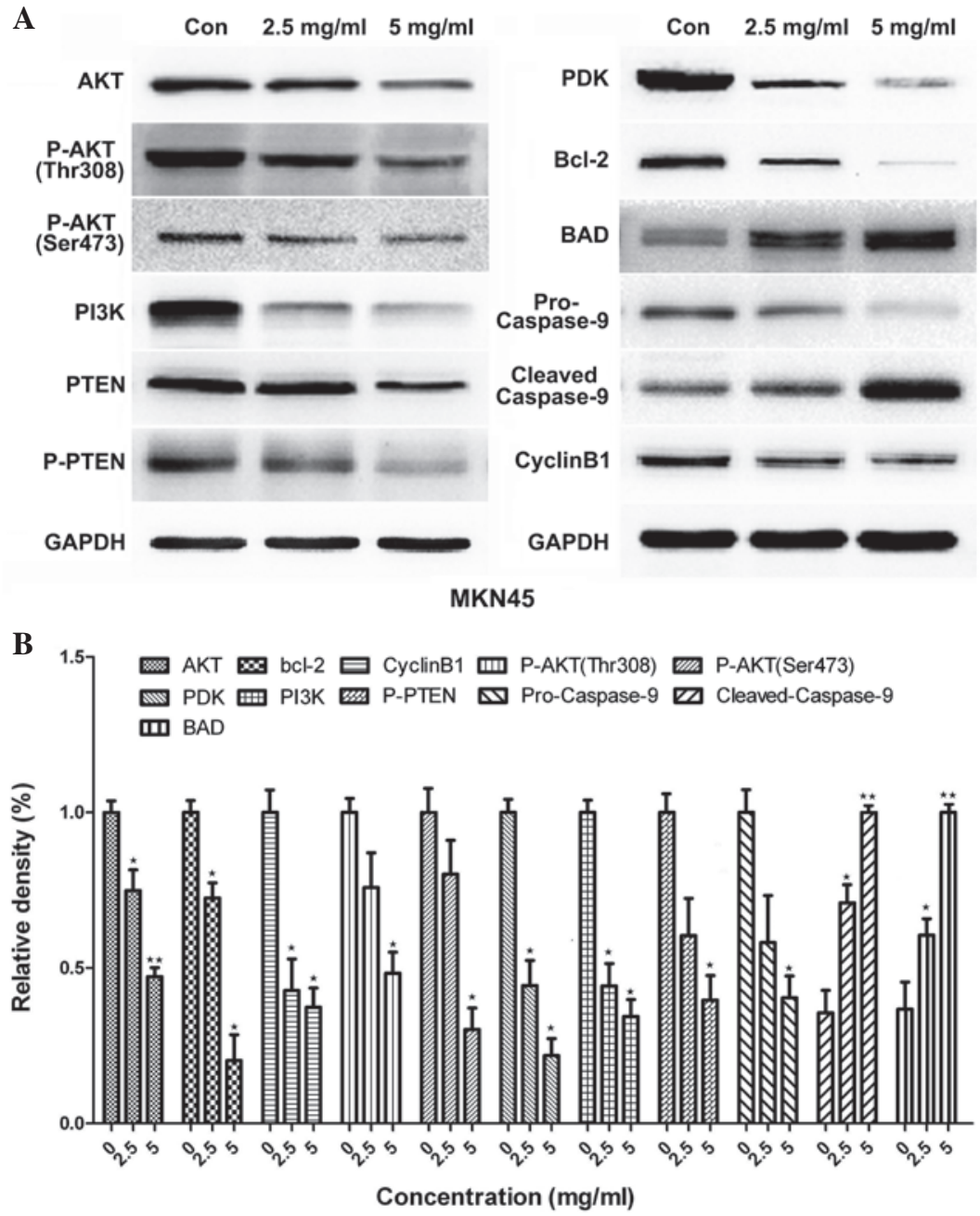

Figure 5. Effect of Huaier extract on the protein expression of AKT1, PI3K, PTEN, PDK1, caspase-9 and Bcl-2. The expression of GAPDH was used as an internal control. MKN45 cells were treated with $0,2.5$ and $5 \mathrm{mg} / \mathrm{ml}$ for $24 \mathrm{~h}$, and (A) western blotting was used to analyze the protein expression. (B) Quantification of the data. The experiment was performed in triplicate, and the data are expressed as the mean \pm standard deviation of the three separate experiments. " $\mathrm{P}<0.05$ and ${ }^{* *} \mathrm{P}<0.01$, compared with the control. p-, phosphorylated-; PI3K, phosphatidylinositol 3-kinase; PTEN, phosphatidylinositol 3,4,5-trisphosphate 3-phosphatase and dual-specificity protein phosphatase; PDK1, pyruvate dehydrogenase kinase isoform 1; Bcl-2, B-cell lymphoma 2; BAD, Bcl-2-associated death promoter.

Human caspase-9 is an initiator of apoptosis (18). The phosphorylation of caspase-9 by PI3K/AKT has been found to lead to an attenuation of its activity (19). Considerable evidence has suggested that among the most important roles of AKT are the enhancement of growth factor-induced cell survival and the inhibition of cell apoptosis. Mammalian cell apoptosis is a process occurring in a series of steps. An early event is the loss of mitochondrial integrity, and this is followed by the release of cytochrome $c$, which is fixed to and activates the apoptotic protease-activating factor (Apaf-1). The activated Apaf-1 then binds to, cleaves and activates cysteine protease and caspase- 9 . The activated caspase- 9 triggers a cascade amplification reaction of proteins of the caspase family (20). In the present study it was found that cleaved-caspase 9 , the activated form of caspase-9, is downregulated following treatment with Huaier. This may contribute to the inhibition of $\mathrm{p}-\mathrm{AKT}$ expression.

Members of the Bcl-2 family are important regulators in the PI3K/AKT pathway. Among the Bcl-2 family are anti-apoptotic effectors, such as Bcl-extra large (Bcl-XL) and Bcl-2, and pro-apoptotic effectors, such as Bcl-associated X protein, BH3 interacting-domain death agonist and
Bcl-2-interacting killer (the BH3 subfamily), as well as BAD and Bcl-2 homologous antagonist/killer (21). When BAD binds to $\mathrm{Bcl}-2$ or $\mathrm{Bcl}-\mathrm{XL}$ and PTEN is phosphorylated by protein kinase $\mathrm{B}(\mathrm{PKB}) / \mathrm{AKT}$, the anti-apoptotic potential of $\mathrm{Bcl}-2$ or Bcl-XL is inhibited. As a result, BAD is regarded as one of the direct targets of the PI3K/AKT pathway in the promotion of cell survival. p-AKT can also mediate cell growth, survival and differentiation, promote anti-apoptotic gene expression, inhibit the c-myc-induced cell apoptosis and regulate the adaptability of cell survival. The present results showed that Huaier could increase the expression of BAD. We inferred that Huaier could promote $\mathrm{BAD}$ release from the complex containing BAD and $\mathrm{Bcl}-2 / \mathrm{Bcl}-\mathrm{XL}$ that is localized on the mitochondrial membrane, leading to increased BAD in the cytoplasm.

In this study, the results of the MTT assay, flow cytometry and western blotting indicated that Huaier played a role in the induction of cell proliferation and apoptosis. The investigation into the effect of Huaier on MKN45 and SGC7901 gastric cancer cell proliferation indicated that Huaier had powerful dose-dependent inhibitory effects and inhibited MKN45 
and SGC7901 human gastric cancer cell proliferation by arresting the cell cycle at $\mathrm{G} 2 / \mathrm{M}$ phase and by modulating the PI3K/AKT signaling pathways. Huaier is capable of upregulating cleaved-caspase-9 expression and downregulating PI3K, p-AKT1, p-PTEN and PDK1 expression. We hypothesize that Huaier inhibits AKT phosphorylation by inhibiting the expression of PI3K and PDK1 and that this reduction in AKT phosphorylation leads to the downregulation of pro-caspase-9 and $\mathrm{Bcl}-2$ expression.

A previous study involving the tissue culture of mammalian cells showed that the Cdc2-cyclin B1 complex is a vital effector for the G2 checkpoint (22). In the present study, it was found that Huaier could significantly decrease the expression of cyclin B1, and the number of cells arrested in the G2/M-phase of the cell cycle was reduced simultaneously. We therefore inferred that the Huaier-induced G2/M-phase cell-cycle arrest and inhibition of cell proliferation occurred through its regulation of cyclin B1 expression.

In conclusion, there are numerous signaling pathways that are important in Huaier-induced apoptosis. Among them, the PI3K/AKT pathway is one of the most critical. The present results suggest that Huaier modulates the PI3K/AKT pathway by inhibiting PI3K expression. This study may facilitate a clearer understanding of the mechanism of Huaier-induced cell apoptosis, and provide a theoretical basis for the antitumor effects of Huaier.

\section{Acknowledgements}

This study was supported by the Zhejiang Provincial Natural Science Foundation (grant nos. LY12H16029 and LY13H160027) and the Key Project of Provincial Administration of Traditional Chinese Medicine (grant no. 2012ZZ002).

\section{References}

1. Ferlay J, Soerjomataram I, Dikshit R, Eser S, Mathers C, Rebelo M, Parkin DM, Forman D and Bray F: Cancer incidence and mortality worldwide: sources, methods and major patterns in GLOBOCAN 2012. Int J Cancer 136: 359-386, 2015.

2. Szakács G, Paterson JK, Ludwig JA, Booth-Genthe C and Gottesman MM: Targeting multidrug resistance in cancer. Nat Rev Drug Discov 5: 219-234, 2006.

3. Li LX, Ye SL, Wang YH and Tang ZZ: Progress on experimental research and clinical application of Trametes robiniophila. Zhong Guo Zhong Liu 16: 110-113, 2007 (In Chinese).
4. Xu X, Wei Q, Wang K, Ling Q, Xie H, Zhou L and Zheng S: Anticancer effects of Huaier are associated with down-regulation of P53. Asian Pac J Cancer Prev 12: 2251-2254, 2011.

5. Zhang N, Kong X, Yan S, Yuan C and Yang Q: Huaier aqueous extract inhibits proliferation of breast cancer cells by inducing apoptosis. Cancer Sci 101: 2375-2383, 2010.

6. Guo Y, Cheng P, Chen Y, Zhou X, Yu P, Li Y, Zhuang Y: Isolation and analysis of the polysaccharide of Huaier mycelium. Chin J Biochem Pharm 63: 56-59, 1993.

7. Ren J, Zheng C, Feng G, Liang H, Xia X, Fang J, Duan X and Zhao H: Inhibitory effect of extract of fungi of Huaier on hepatocellular carcinoma cells. J Huazhong Univ Sci Technolog Med Sci 29: 198-201, 2009.

8. Xu X, Wei Q, Wang K, Ling Q, Xie H, Zhou L and Zheng S: Anticancer effects of Huaier are associated with down-regulation of P53. Asian Pac J Cancer Prev 12: 2251-2254, 2011.

9. Cheng YL, Chang WL, Lee SC, Liu YG, Chen CJ, Lin SZ, et al: Acetone extract of Angelica sinensis inhibits proliferation of human cancer cells via inducing cell cycle arrest and apoptosis. Life Sci 75: 1579-1594, 2004.

10. Wang X, Zhang N, Huo Q, Sun M, Lv S and Yang Q: Huaier aqueous extract suppresses human breast cancer cell proliferation through inhibition of estrogen receptor $\alpha$ signaling. Int J Oncol 43: 321-328, 2013.

11. Sun Y, Sun T, Wang F, Zhang J, Li C, Chen X, Li Q and Sun S: A polysaccharide from the fungi of Huaier exhibits anti-tumor potential and immunomodulatory effects. Carbohydr Polym 92: 577-582, 2013.

12. Zhang F, Zhang Z, Liu Z: Effects of Huaier aqueous extract on proliferation and apoptosis in the melanoma cell line A875. Acta Histochemica 115: 705-711, 2013.

13. Zhang T, Wang K, Zhang J, Wang X, Chen Z, Ni C, Qiu F and Huang J: Huaier aqueous extract inhibits colorectal cancer stem cell growth partially via downregulation of the Wnt/ $\beta$-catenin pathway. Oncol Lett 5: 1171-1176, 2013.

14. Yan X, Lyu T, Jia N, Yu Y, Hua K and Feng W: Huaier aqueous extract inhibits ovarian cancer cell motility via the AKT/GSK3// $\beta$-catenin pathway. PLoS One 8: e63731, 2013.

15. Kumar A and Carrera AC: New functions for PI3K in the control of cell division. Cell Cycle 6: 1696-1698, 2007.

16. Song G, Ouyang G and Bao S: The activation of Akt/PKB signaling pathway and cell survival. J Cell Mol Med 9: 59-71, 2005.

17. Hafsi S, Pezzino FM, Candido S, Ligresti G, Spandidos DA, Soua Z, McCubrey JA, Travali S and Libra M: Gene alterations in the PI3K/PTEN/AKT pathway as a mechanism of drug-resistance (review). Int J Oncol 40: 639-644, 2012.

18. Donepudi M and Grütter MG: Structure and zymogen activation of caspases. Biophys Chem 10: 145-153, 2002.

19. Cardone MH, Roy N, Stennicke HR, Salvesen GS, Franke TF, Stanbridge E, Frisch S and Reed JC: Regulation of cell death protease caspase-9 by phosphorylation. Science 282: 1318-1321, 1998.

20. Allan LA and Clarke PR: Apoptosis and autophagy: Regulation of caspase-9 by phosphorylation. FEBS J 276: 6063-6073, 2009.

21. Adams JM and Cory S: The Bcl-2 protein family: Arbiters of cell survival. Science 281: 1322-1326, 1998.

22. Stark GR and Taylor WR: Analyzing the G2/M checkpoint. Methods Mol Biol 280: 51-82, 2004. 